\title{
Combustion Fault Simulation of Diesel Engine Based on AVL-FIRE Software
}

\author{
Junfu YUAN ${ }^{1}$ and Chunsheng ZHAO \\ College of Marine Electrical and Intelligent Engineering, Jiangsu Maritime Institute, \\ Nanjing, Jiangsu, China
}

\begin{abstract}
Marine diesel engine is developing towards the direction of precision, automation and systematization, and it has the characteristics of complex structure and many parts. If it breaks down, it will affect the operation safety of the whole ship. If it is serious, accidents may occur, which may cause maritime accidents. Therefore, how to prevent the occurrence of marine diesel engine failure and analyze the cause of failure after the accident has been paid more and more attention by scholars at home and abroad. In the simulation study of the working process of diesel engine, for different types of diesel engines, the laws of combustion process are different, even for the same diesel engine in different working conditions, the combustion laws are also different, which will cause great difficulties to study the combustion process. Using computer simulation technology, the physical calculation model of diesel engine system is established by simulating the typical combustion faults of marine diesel engine. AVL-FIRE software is used to simulate different faults of diesel engine combustion process, and the changes of various performance parameters of diesel engine under corresponding faults are obtained, so as to grasp its working state macroscopically, and provide relevant basis for the design, optimization and operation management of diesel engine system.
\end{abstract}

Keywords. Diesel engine system, typical combustion faults, combustion process

\section{Introduction}

The fuel injection system of diesel engine is one of the most important systems of diesel engine. Its main function is to provide fuel for the formation and combustion of mixture in cylinder. It has a direct impact on the combustion of diesel engine and a series of performance indicators such as power performance, economy, reliability, emission characteristics and starting performance of diesel engine. Since the birth of diesel engine, the fuel injection and combustion of diesel engine have been paid close attention, and a lot of research has been done [1]. With the development and application of modern testing technology and means, the research on fuel injection and combustion of diesel engine has been improved to a new stage, which makes people have a deeper understanding of the combustion process of diesel engine and promotes the development of diesel engine development and manufacturing technology.

Marine diesel engine is an important power equipment of the ship, which is directly related to the safe navigation and normal operation of the ship [2]. Therefore, it

${ }^{1}$ Corresponding Author, Junfu YUAN, College of Marine Electrical and Intelligent Engineering, Jiangsu Maritime Institute, Nanjing, Jiangsu, China; Email: yujufu@163.com. 
is necessary to correctly understand the structure, principle and performance characteristics of marine diesel engine, so as to lay a good foundation for the correct disassembly and operation of marine diesel engine.

\section{Calculation Hypothesis and Model Establishment of Thermal Process of Diesel Engine}

\subsection{Relevant Theory}

When the piston is close to the top dead center, the fuel injection system injects the fuel into the cylinder with high pressure in a very short time to realize the mixing and combustion of fuel and air. Therefore, whether in the manufacturing and adjustment accuracy [3], or in the matching with the whole machine, the requirements of the fuel injection system are very strict. In order to ensure the diesel engine in power, economy, emissions and noise to achieve excellent performance.

The process of fuel injection is a complex physical process. In the process of injection, the physical process in the high-pressure system from the fuel pump outlet valve to the injector needle valve is affected by the compressibility of the fuel, the elasticity of the high-pressure fuel pipe, the throttling of the system and the inertia of the fuel movement. These factors cause time delay and pressure fluctuation in the process of fuel injection, and then affect the quality of fuel injection.

\subsection{Model Development}

This paper uses MAN B\&W 6S50MC diesel engine block system arrangement and AVL-FIRE software to establish the calculation model of diesel engine working process (figure 1). Without affecting the simulation effect, in order to facilitate the calculation, the components with weak influence on the performance of diesel engine are properly simplified [4].

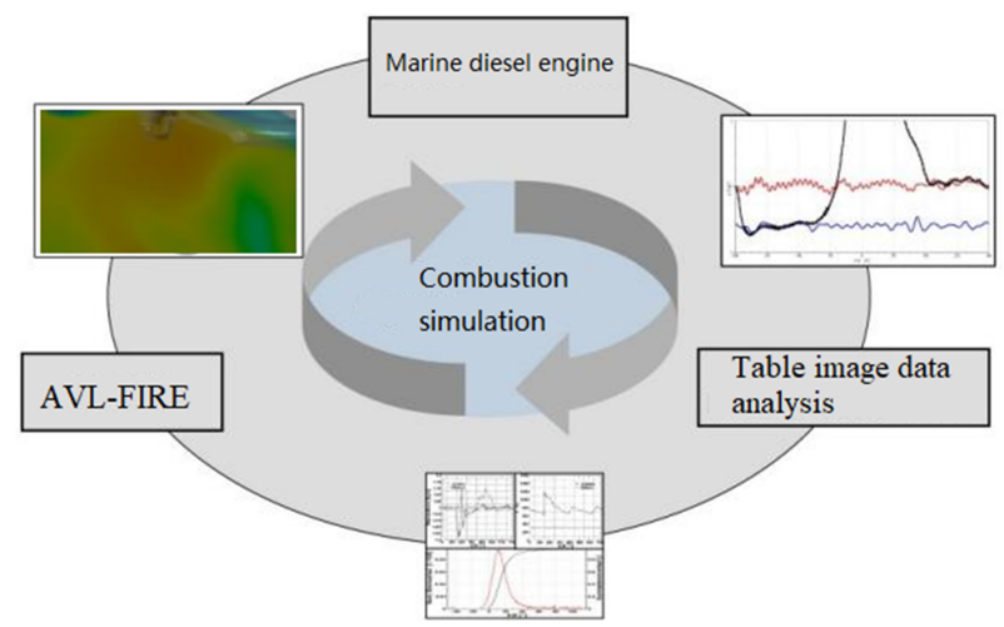

Figure 1. Calculation model of combustion process of diesel engine. 


\section{Diesel Engine Fault Simulation}

\subsection{Oil Supply Law of Diesel Engine}

The fuel supply law can be calculated according to the geometric parameters of the fuel injection pump, and the fuel injection law is determined by the geometric parameters of the fuel injection system and the hydraulic characteristics of the fuel under high pressure. There is a certain internal relationship between them. The fuel injection law is affected by the fuel supply law. The starting point of the fuel injection is later than the starting point of the fuel injection, and the fuel injection duration is longer than the fuel supply duration, The peak value of injection rate is less than that of injection rate [5].

In a multi cylinder diesel engine, due to the difference of the clearance between the plunger couple of the injection pump, the needle valve couple of the injector and the diameter of the injection hole, as well as the difference of the installation clearance of the adjusting rod of the oil pump, the fuel supply of each cylinder of the marine main diesel engine is significantly uneven at low speed (low load). In serious cases, individual cylinder can not be ignited, which makes the speed unstable, and even stops automatically.

In the diesel engine, the process of injecting fuel into the cylinder under high pressure and dispersing it into small and small droplets is called fuel spray or atomization (table 1). Its purpose is to greatly increase the surface area of fuel evaporation, so as to accelerate the heat absorption and gasification process of fuel, and then accelerate the mixing of fuel and air (figure 1).

Table 1. Comparison of failure parameters of single cylinder oil stopping.

\begin{tabular}{|c|c|c|c|c|c|c|c|}
\hline \multirow[b]{2}{*}{ Indicators } & \multirow{2}{*}{$\begin{array}{l}\text { Effective } \\
\text { s power } \\
(\mathrm{KW})\end{array}$} & \multirow{2}{*}{$\begin{array}{l}\text { Effective } \\
\text { torque } \\
\text { (NM) }\end{array}$} & \multirow{2}{*}{$\begin{array}{l}\text { Fuel } \\
\text { consumption } \\
\text { rate } \\
(\mathrm{g} / \mathbf{k w * h}) \\
\end{array}$} & \multirow{2}{*}{$\begin{array}{l}\text { Indicator } \\
\text { pressure } \\
\text { (MP) }\end{array}$} & \multirow{2}{*}{$\begin{array}{l}\text { Exhaust } \\
\text { temperature in fron } \\
\text { of turbine }\left({ }^{\circ} \mathrm{C}\right)\end{array}$} & \multicolumn{2}{|c|}{ Fuel delivery (ml/weeks) } \\
\hline & & & & & & Single cylinder & Total cylinder \\
\hline Normal & 9302.18 & 709493 & 186.36 & 1.567 & 697.7 & 37.03 & 223.62 \\
\hline $\begin{array}{l}\text { A cylinder } \\
\text { shutdown }\end{array}$ & 7805.08 & 592261 & 183.48 & 1.612 & 675.9 & 38.21 & 185.67 \\
\hline $\begin{array}{l}\text { Difference } \\
(\%)\end{array}$ & 17.4 & 17.6 & 0.76 & 15.98 & 7.9 & 0 & 13.7 \\
\hline
\end{tabular}

The scientific maintenance and management of the fuel injection system can extend the service life of the fuel injection equipment, reduce the probability of failure, ensure good fuel injection law and heat release law, and make the diesel engine run smoothly and efficiently [6]. The maximum pressure value in the cylinder of diesel engine is the pressure value of compression end point (figure 2).

When cylinder 2 stops running and the diesel engine continues, the maximum combustion temperature in the cylinder decreased significantly [7] (figures 3 and 4). To ensure the reliability of the diesel engine. When the single cylinder of the diesel engine fails and has to stall, the diesel engine should be slowed down; Except in exceptional circumstances, it is forbidden to work continuously for a long time after single cylinder flameout of diesel engine. 


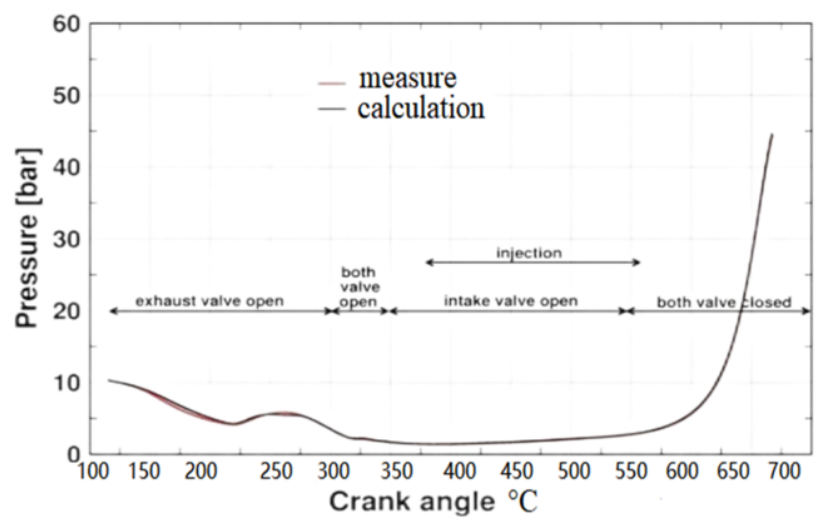

Figure 2. Pressure history for the gas exchange simulation.

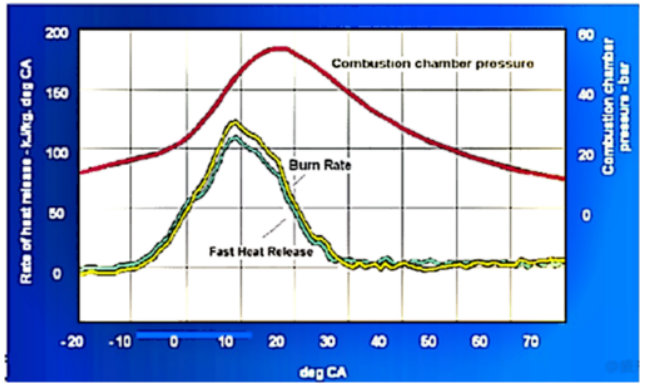

Figure 3. Comparison curve of total pressure in single cylinder before and after stopping oil.

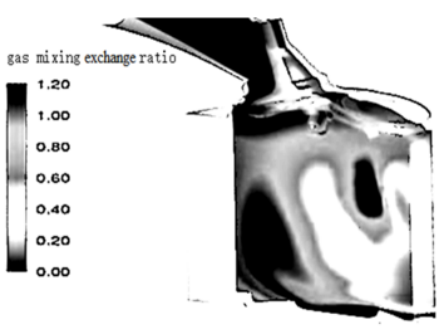

Figure 4. The oil gas mixing exchange simulation results.

\subsection{Diesel Fuel System Fault}

The fuel injection equipment needs to be disassembled and tested in time to find out the hidden dangers and defects and eliminate them in time. Pay attention to cleaning during disassembly and inspection. Only light diesel oil is allowed to be used for cleaning, and cotton yarn is not allowed to be used for wiping. When reassembling, pay attention to the correct positioning, the combination of each sealing surface, and the relevant assembly marks [8].

During standby, the oil pump of each cylinder should be manually pumped one by one to lubricate the plunger couple and observe the flexibility of the plunger and its related moving parts. In addition, it is necessary to check the accuracy and reliability of the action of the fuel regulating mechanism of the fuel injection pump.

After a long-term shutdown or after the fuel injection equipment is disassembled, inspected and reassembled, pay attention to the venting of the fuel injection equipment and fuel system. There shall be no fuel leakage in the fuel injection equipment.

In this paper, AVL-FIRE software is used to simulate the changes of diesel engine performance parameters caused by relevant faults by changing exhaust valve timing. If the opening and closing value of the exhaust valve of diesel engine No. 2 cylinder is set to the following four cases: the normal state is set to $110^{\circ}$ the crankshaft angle is opened, $274^{\circ}$ Crankshaft angle closed; A slight fault condition set to $114^{\circ}$ crank angle 
open, $270^{\circ}$ Crankshaft angle closed; A medium fault state of $118^{\circ}$ crank angle open, $266^{\circ}$ Crankshaft angle closed; A serious failure condition of $122^{\circ}$ crank angle open, $262^{\circ}$ Crankshaft corner closed [7] (table 2).

Table 2. Exhaust timing fault parameters.

\begin{tabular}{llllllll}
\hline $\begin{array}{l}\text { Exhaust } \\
\text { valve } \\
\text { switch } \\
\text { setting }\end{array}$ & $\begin{array}{l}\text { Exhaust } \\
\text { valve timing } \\
\text { (duration } \\
\text { angle) }\left({ }^{\circ} \mathbf{C}\right)\end{array}$ & $\begin{array}{l}\text { Effective } \\
\text { power } \\
(\mathbf{k W})\end{array}$ & $\begin{array}{l}\text { Effective fuel } \\
\text { consumption } \\
\text { rate }(\mathbf{g} / \mathbf{k W} \cdot \mathbf{h})\end{array}$ & $\begin{array}{l}\text { Average } \\
\text { indicator } \\
\text { pressure } \\
\mathbf{( M P a )}\end{array}$ & $\begin{array}{l}\text { Cylinder } \\
\text { exhaust } \\
\text { temperature } \\
(\mathbf{K})\end{array}$ & $\begin{array}{l}\text { Scavenging } \\
\text { efficiency }\end{array}$ & $\begin{array}{l}\text { Scavenging } \\
\text { coefficient }\end{array}$ \\
\hline Normal & $113-268$ & 9468 & 178.12 & 1.861 & 532 & 0.889 & 1.38 \\
Slight & $116-275$ & 9236 & 181.65 & 1.896 & 541 & 0.875 & 1.37 \\
Serious & $121-271$ & 8628 & 196.86 & 1.789 & 785 & 0.778 & 1.42 \\
\hline
\end{tabular}

The change of exhaust timing of No.2 cylinder of diesel engine has little effect on the medium pressure in the cylinder [9] (figure 5), but the change of temperature in the cylinder is more significant, and with the decrease of the continuous angle of exhaust, the temperature in the cylinder increases gradually. When the diesel engine is used as the main engine of the ship, it works with the propeller. For a given diesel engine, a suitable propeller must be selected (figure 6). The proper matching of diesel engine and propeller should not only make full use of the power of diesel engine, but also ensure that the power of diesel engine does not exceed the allowable range within the whole operating speed range [10]. In this way, the diesel engine can give full play to its function and obtain high economy, reliability and long service life.

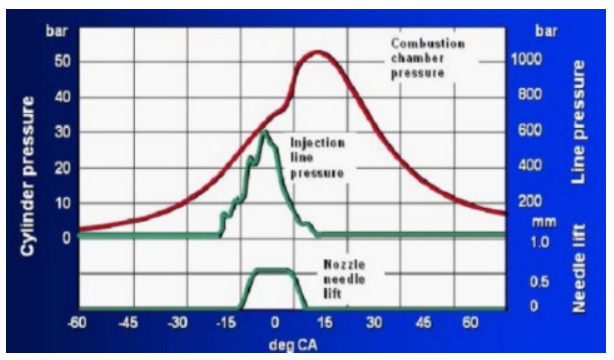

Figure 5. Comparison curve of total pressure in two more cylinder before and after stopping oil.

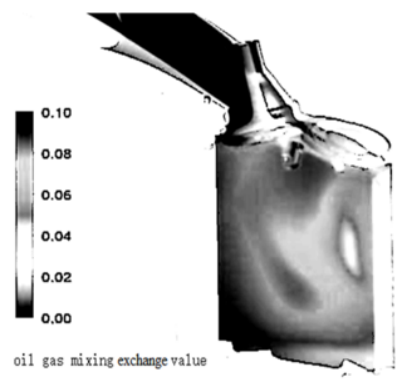

Figure 6. The oil gas mixing exchange simulation results.

\section{Conclusion}

The simulation results of diesel engine combustion process can be used for reference, which verifies the effectiveness of the simulation model. If the simulation model can be modularized, the simulation results can be quickly analyzed, and the correct simulation results can be quickly obtained, which makes the simulation more convenient.

\section{References}

[1] Zeng Q, Huang L, Jin J, Sang X, Wei P and Qin C 2021 Simulation study on correlation between typical faults and combustion parameters of diesel engine Diesel Engine 43 (01) 19-25. (in Chinese) 
[2] Liu C P, G Y, Liu T and Tu D H 2020 Effect of nozzle structure on combustion of marine low speed diesel engine Internal Combustion Engine and Power Plant 37 (04) 1-7+13. (in Chinese)

[3] Yang K, Sun K, Lu Z, Wang T and Wang H 2020 Effect of multi injector staged injection on combustion and emission of large bore low speed diesel engine Internal Combustion Engine Engineering 41 (03) 27-34. (in Chinese)

[4] Sun X, Tan Q, Zeng X and Zhou D 2018 Combustion fault diagnosis of marine low speed diesel engine based on fuel consumption rate China Navigation 41 (04) 23-27. (in Chinese)

[5] Ren C H, Xie X P and Shen J 2018 Mechanism analysis and fault simulation research on low cylinder temperature of diesel engine Marine Electronic Engineering 38 (05) 67-71+76. (in Chinese)

[6] Zhu X 2016 Research on Diesel Engine Fault Diagnosis Method Based on KNN Algorithm (Harbin Engineering University) (in Chinese)

[7] Zhao C 2014 Typical fault simulation of diesel engine based on boost software Water Transportation Management 36 (08) 32-34. (in Chinese)

[8] China Maritime Service Center 2012 Ship Main Propulsion Power Plant (Dalian: Dalian Maritime University Press) pp 405-438. (in Chinese)

[9] Cheng Q B, Lu L L, Geng L M and Wang C 2016 Simulation of in-cylinder combustion of diesel engine based on AVL-FIRE Automobile Practical Technology (11) 28-29. (in Chinese)

[10] Wang H and Liu H T 2016 Simulation of diesel engine cylinder combustion process Hebei Agricultural Machinery (02) 25-26. (in Chinese) 